\title{
FREINET, VIGOTSKY E BAKHTIN: UMA APROXIMAÇÃO POSSÍVEL AO ACESSO À CULTURA ESCRITA
}

\author{
FREINET, VIGOSTKY Y BAKHTIN: UN POSIBLE ENFOQUE PARA ACCEDER \\ A LA ESCRITURA CULTURA
}

\author{
FREINET, VIGOSTKY AND BAKHTIN: A POSSIBLE APPROACH TO ACCESS \\ WRITING CULTURE
}

\author{
Cyntia Graziella Guizellim Simões GIROTTO ${ }^{1}$ \\ Greice FERREIRA DA SILVA ${ }^{2}$ \\ Cassiana MAGALHÃES ${ }^{3}$
}

RESUMO: Objetiva-se neste estudo refletir sobre as práticas pedagógicas acerca da cultura da leitura e da escrita do ponto de vista dos pressupostos da Teoria HistóricoCultural (THC) e da teoria da enunciação de Bakhtin, buscando um possível diálogo com os ideários do pensamento de Freinet e suas técnicas. Trata-se de uma pesquisa realizada em uma instituição pública municipal do interior paulista com crianças de cinco e seis anos de idade. O critério para a escolha da turma se deu pelo fato de as crianças terem experiências no contexto das técnicas Freinet na escola. Após a recolha e análise cuidadosa dos dados, é possível afirmar que existe possibilidade de diálogo entre os autores Freinet, Vigotsky e Bakhtin, e, principalmente, a apropriação teórica, por parte dos professores, dessa aproximação existente, potencializa as práticas pedagógicas acerca da leitura e da escrita.

PALAVRAS-CHAVE: Práticas Pedagógicas. Teoria Histórico-Cultural. Pensamento freinetiano. Cultura escrita. Leitura.

RESUMEN: El objetivo de este estudio es reflexionar sobre las prácticas pedagógicas sobre la cultura de la lectura y la escritura desde la perspectiva de la Teoría HistóricoCultural (THC) y la teoría de la enunciación de Bakhtin, buscando un posible diálogo con los ideales del pensamiento y las técnicas de Freinet. Se trata de una investigación realizada en una institución pública municipal del interior del estado de São Paulo con niños de cinco y seis años. El criterio para elegir el grupo se debió al hecho de que los niños tuvieran experiencias en la escuela en el contexto de las técnicas de Freinet. Después de la recolección de datos y el análisis cuidadoso, es posible afirmar que existe una posibilidad de diálogo entre Freinet, Vigotsky y Bakhtin, y, sobre todo, la

\footnotetext{
${ }^{1}$ Universidade Estadual Paulista (Unesp), Marília - SP - Brasil. Departamento de Didática, onde integra o corpo docente da graduação em Pedagogia. Livre-docente em Leitura e Escrita. E-mail: cyntiaunespmarilia@gmail.com.

${ }^{2}$ Universidade Estadual de Londrina (Uel), Londrina - PR - Brasil. Professora Adjunto do Departamento de Educação da Universidade Estadual de Londrina. E-mail: grebalet@terra.com.br.

3 Universidade Estadual de Londrina (Uel), Londrina - PR - Brasil. Docente do Departamento de Educação da Universidade Estadual de Londrina. E-mail: magalhaes.cassiana@gmail.com.
}

RIAEE - Revista Ibero-Americana de Estudos em Educação, Araraquara, v. 13, n. 1, p. 155-174, jan./mar., 2018. 
apropiación teórica por parte del profesor de esta aproximación existente potencia las prácticas pedagógicas sobre lectura y escritura.

PALABRAS CLAVE: Prácticas Pedagógicas. Teoría Histórico-Cultural. Pensamiento de freinetiano. Cultura escrita. Lectura.

ABSTRACT: This study aims to reflect on pedagogical practices about the culture of reading and writing from the perspective of the Cultural-Historical Theory $(\mathrm{CHT})$ and Bakhtin's theory of enunciation, seeking a possible dialogue with the ideals of Freinet's thinking and techniques. It is a research carried out in a public municipal institution of São Paulo State countryside with five and six-year-old children. The criterion for class selection was the fact that the children had experiences in school in the context of Freinet's techniques. After data collection and careful analysis, it is possible to affirm that there is a possibility of dialogue between Freinet, Vigotsky and Bakhtin, and, mainly, teacher's theoretical appropriation of this existing approximation potentiates the pedagogical practices about reading and writing.

KEYWORDS: Pedagogical Practices. Historical-Cultural Theory. Freinetian thinking. Written culture. Reading.

\section{Introdução}

As práticas culturais de leitura e de escrita, para além dos processos de ensino e de aprendizagem da educação formal, constituem, há décadas, um tema controverso e complexo nas ciências humanas e sociais por seu alcance político e suas implicações na vida social e de cada pessoa em sua singularidade. Este estudo focalizou a essência dessas práticas culturais pela ótica dos autores Freinet, Vigostky e Bakhtin.

Nesse sentido, o propósito neste estudo foi o de analisar as práticas pedagógicas acerca da leitura e da escrita do ponto de vista dos pressupostos de Vigotsky e Bakhtin. No entanto, as atividades veiculadas nas escolas estão bem mais próximas do pensamento freinetiano. Para tanto, a observação das práticas pedagógicas possibilitounos analisar as práticas culturais de leitura e escrita, muitas vezes fundamentada no pensamento freinetiano, sob o enfoque dos estudos da Teoria Histórico-Cultural e dos enunciados bakhtinianos, em que se debate essa essência da prática pedagógica em seus aspectos históricos, socioculturais, cognitivos e afetivos.

Frente a esta possível relação teórica, o presente estudo correlaciona o contexto das práticas de leitura e escrita pautadas nos pressupostos freinetianos e sua possível relação com a teoria histórico-cultural e a teoria da enunciação de Bakhtin.

RIAEE - Revista Ibero-Americana de Estudos em Educação, Araraquara, v. 13, n. 1, p. 155-174, jan./mar., 2018. 


\section{Freinet, Vigotsky e Bakhtin: uma possibilidade no contexto das práticas de leitura e escrita}

Assim, este estudo problematiza-se, direta ou indiretamente, a atualidade e o legado de um professor autodidata em pesquisa pedagógica, pouco reconhecido no meio acadêmico e pouco divulgado, e, prioritariamente, pouco estudado em sua filosofia de ensino e em suas técnicas, na esfera da formação inicial e contínua de professores.

O fato de se ter ou não acesso a essas práticas, de ter possibilidade de apropriação dessa capacidade especificamente humana de ler e de escrever, de ser ou não privado desses bens imateriais, evidenciando-se suas repercussões sobre as condições de letrado ou de iletrado, de inserção ou exclusão profissional, a divisão entre saberes eruditos e populares, a percepção do urbano e do rural, a oposição entre civilização e barbárie, é urgente neste milênio.

Correlata às atribuições da escola da infância de promover a universalização da leitura e da escrita, outros subtemas de igual interesse, tais como autoridade e poder face à vida em cooperação entre as crianças e seus pares e os professores; mecanização do ensino, dos atos de leitura e escrita; autonomia, trabalho e empoderamento nas atividades genuínas de leitura e escrita; atitude responsiva e enunciados, versus a mera sinalidade na escrita; desenvolvimento psíquico atrelado em sua complexificação ao desenvolvimento da linguagem, perpassam o conjunto das ideais aqui exploradas. Retomam-se aqui as contribuições, portanto, de Célestin Freinet sobre a educação como espaço democrático e de cooperação, onde podem ser aprendidas as capacidades genuínas de ler e escrever. Esta última noção, eleita como tema central da II Bienal da Educação (Paris, 2015), insere-se numa nova "cultura da ação", que é rica em aberturas para a pesquisa pedagógica sobre a ação coletiva, a coparticipação, a experiência, o acompanhamento, na linguagem freinetiana, na experimentação, no tateio.

Afinal, diversos pensadores de diversas vertentes, mas em especial os da Teoria Histórico-Cultural, sustentam a viabilidade do exercício da educação motivado pelo interesse, necessidade e desejo infantil, exponencialmente multiplicado, quando o professor constitui-se como um criador de novas necessidades humanizadoras, quais sejam, a de ler e escrever, envolvidos em práticas compartilhadas na quais aqueles detêm um papel ativo, exercido por ações genuínas, na condição de práticas culturalmente constituídas.

Entre os educadores preocupados com o dia-a-dia da sala de aula e que possuem tal entendimento, ainda que não tenha dialogado à sua época com Vigotski e Bakhtin, 
pode-se destacar Célestin Freinet. Apoiadas em Vigotski (1995) e Bakhtin (1992 e 2004), concebemos a apropriação do ato de ler e de escrever como capacidades forjadas há milênios, e que invariavelmente vem desenvolvendo o psiquismo humano sob o prisma filogenético e ontogenético.

Em atuação na França entre as décadas de 1920 e 1960, Freinet, ao longo de sua vivência docente em sala de aula, fundou na escola pública de seu país uma pedagogia marcada pela apropriação do trabalho como ação vívida, coletiva e educacional (SAMPAIO, 1994). Tal pedagogia, apropriando-se de tecnologias na escola, busca o aprendizado pela prática em conjunto voltada para o desenvolvimento, entre as crianças, de uma aproximação produtiva e da liberdade como aspecto fundamental. Tais pontos constituem a concepção filosófica freinetiana, como a de cooperação, um dos eixos centrais desta pedagogia (FREINET, 1998).

No entanto, além da cooperação, o trabalho, a comunicação e a autonomia são eixos centrais, configuram-se como base da concepção do professor francês Célestin Freinet na direção da entrada da criança no universo da cultura escrita, base para a apropriação da linguagem escrita. Contudo, cabe salientar que a utilização da perspectiva freinetiana não corresponde à destituição de outras visões acerca da cooperação, mas consiste na opção pelo seguimento de um norteador relevante para o desenvolvimento de uma educação em que a criança é ativa, ocupando um lugar de protagonismo na produção daqueles que nela se envolvem.

Vale lembrar, portanto, que o lugar ocupado pela criança nas relações sociais das quais participa tem força motivadora em seu desenvolvimento (LEONTIEV, 1998). As expectativas apontadas para a criança pelas pessoas mais próximas a ela vão motivando seu desenvolvimento, de forma que tratada como alguém que é capaz de aprender, a criança tem mais chances de aprender; por outro lado, se tratada como alguém que aprende espontaneamente e, por isso, incapaz de determinadas aprendizagens, que subentendem um nível de desenvolvimento, as oportunidades de aprendizado e desenvolvimento acontecerão em situações mais escassas e serão, assim, determinantes de sua experiência restrita e de seu desenvolvimento igualmente restrito.

Anterior à elaboração de sua perspectiva de cooperação, Freinet realizou na pedagogia que leva seu sobrenome a retomada educativa de uma palavra que, apropriada por perspectivas mercantis, representa uma acepção ligada quase que estritamente à aquisição financeira e material. Trata-se do termo "trabalho". Para Freinet (1998), ligado à tradição marxista, o trabalho suplanta a ideia de estrito objeto 
produtivo voltado para o escambo financeiro. Em suas concepções pedagógicas, o autor concebe a noção de trabalho como oposta a uma perspectiva de "tarefa obrigatória, que nos sujeita, da qual nos esquivamos tão logo seja possível, mediante más ações, se necessárias [...]" (FREINET, 1998, p. 333). O trabalho é entendido pelo autor como um exercício de vida, movimento inerente a homens e mulheres em relações efetivadas por meio de uma atmosfera fraterna, generosa e justa. Emerge nesse contexto um referencial no qual a noção de "aprender a fazer fazendo" adquire ares centrais para o crescimento educativo.

Por isso, com Vigotski e Leontiev compreendemos trabalho na visão freinetiana como atividade. Segundo a perspectiva histórico-cultural, não é qualquer tarefa que pode ser designada como tal, mas aquela que se constitui, propriamente, como atividade. $\mathrm{O}$ conceito de atividade é para essa pesquisa um conceito essencial, uma vez que o processo de apropriação da cultura está intimamente ligado à atividade da criança. Por atividade compreendemos aquela que a criança realiza motivada por seus objetivos. Nas palavras de Leontiev (1998, p. 68), “[...] os processos psicologicamente caracterizados por aquilo a que o processo, como um todo, se dirige (seu objeto), coincidindo com o objetivo que estimula o sujeito a exercitar esta atividade, isto é, o motivo". Por esse norteador, o trabalho, e, mais especialmente, o compartilhado pelos sujeitos, constitui por servir como esfera de convivência, um aspecto basilar na formação educativa das crianças. Assim, chega-se à noção de cooperação de Freinet, que compreende o compartilhar do trabalho educativo.

A cooperação freinetiana elenca o trabalho como instância de encontro das crianças para a ação de aprender, rejeitando a ideia de uma educação preconcebida em manuais escolares, "ciência fria" nas palavras do autor (FREINET, 1975, p. 54), em favor do exercício em conjunto da elaboração laboral do conhecimento. Como sujeitos inseridos nesse processo, as crianças apropriam-se criticamente das informações disponíveis envoltas em uma atmosfera relacional produtiva, pela qual podem tatear o mundo, examinando-o por meio de seus objetos, locais e meios expressivos. A perspectiva esclarecida é demonstrada pela pedagogia Freinet em diversas práticas, como aulas-passeio, que levam as crianças ao encontro direto com lugares sobre os quais, anteriormente, apenas poderiam abstrair; correspondência interescolar, promotora do contato aberto com realidades de colegas que estejam distantes por meio da troca de cartas; uso pedagógico de tecnologias, o qual oferece o aprendizado ao indivíduo pelo tateamento produtivo livre na elaboração de conteúdos por meio de tecnologias; texto 
livre, viabilizador da expressividade liberta dos sujeitos, o que ocorre mediante o oferecimento aos alunos da possibilidade de realizações produtivas em diversos meios cinema, jornal, desenho, áudio, dentre outros (FREINET, 1977).

Partindo-se das concepções de Freinet, a administração de situações inclusive conflituosas e/ou difíceis e afins poderia ocorrer a partir de uma resolução democrática, pautada na decisão coletiva dos alunos. Seria possível, para isso, construir um desenvolvimento laboral guiado "por votos de mão levantada" (FREINET, 1974, p. 21), no qual a realização de assembleias para votação de questões pertinentes tornar-se-ia uma ação periódica. Além disso, o levantamento de críticas, sugestões e elogios na produção em questão poderia apropriar-se das ideias de Freinet por meio de ações em que "através de bilhetes, os alunos seriam estimulados a escrever, individualmente, suas opiniões na forma de 'eu proponho', 'eu critico' e 'eu felicito’”. Dessa maneira, seriam reunidas práticas para a organização das relações produtivas vivenciadas, auxiliando no alcance de um desenvolvimento mais lúcido e bem elaborado por parte dos alunos.

Destaca-se resultados positivos da Pedagogia Freinet em escola parceira de nossas pesquisas entre os anos de 2013 a 2015, em que as crianças, estando em atividade, mediante uma vida cooperativa, exercem o desejo de expressão, de comunicação, da vivência da cultura escrita por necessidades humanizadoras geradas no coletivo na direção do desenvolvimento da autonomia, um modo de relação 'produtiva' que repercute as palavras de Freinet (1998, p. 335) quando estas asseveram que "a verdadeira fraternidade é a fraternidade do trabalho". Vale dizer, para nós, tanto entre educadores quanto entre crianças.

A realização de álbuns produzidos, livros da vida, assembleias, organização de espaços de aprendizagem, vivência do jornal da turma e do jornal de parede, as rodas de conversa, dentre outras técnicas, no conjunto, espelham o desejo de expressão sendo cultivado desde a mais tenra idade, na Educação da Infância. A cada uma das objetivações expostas na própria escola e divulgadas em eventos científicos, reiteram conceitos dos pesquisadores russos que justificam e qualificam ainda mais as ideias deste grande humanista, que a sua época celebrava a vida junto das crianças justamente motivado e enredado pelo êxito de cada uma delas, no conjunto da turma e da escola.

Para Freinet, a língua deveria ser ensinada em sua pujança, criando o desejo humanizador de expressão nas crianças por meio de diversas atividades e documentações pedagógicas, mediante as quais elas pudessem se comunicar. A língua, neste caso, não poderia e não pode ser vista apenas como um sinal, como comumente é

RIAEE - Revista Ibero-Americana de Estudos em Educação, Araraquara, v. 13, n. 1, p. 155-174, jan./mar., 2018. 
ensinada nas escolas, uma vez que uma letra pouco pode comunicar. Ao conceber o foco do ensino da linguagem escrita na letra, o discurso não acontece, pois para que esse exista torna-se necessário as enunciações. Bakhtin (2004, p. 265) permite-nos compreender tais processos ao asseverar que "a língua passa a integrar a vida através de enunciados concretos (que a realizam); é igualmente através de enunciados concretos que a vida entra na língua”. Desse ponto de vista, se há o priorizar, meramente, do ensino da letra, a escola debilita as relações da língua com a vida, sendo que a instituição de educação formal poderia ser um ambiente que ensina aos indivíduos práticas discursivas e enunciativas.

Defendemos neste estudo a linguagem como signo e não como um sinal gráfico. Para a criança, aprender a lidar com os signos, se comunicar por meio deles, é uma atividade complexa. Vigotsky (1995, p. 184) já afirmava que: “o domínio da linguagem escrita significa para a criança dominar um sistema extremamente complexo de signos simbólicos". Nessa mesma linha de pensamento, ou seja, de entender a linguagem como signo, e não como sinal, está a ideia de Bakhtin (2004, p. 94) ao explicar que:

Enquanto uma forma linguística for apenas um sinal e for percebida pelo receptor somente como tal, ela não terá para ele nenhum valor linguístico. A pura "sinalidade" não existe, mesmo nas primeiras fases da aquisição da linguagem. Até mesmo ali, a forma é orientada pelo contexto, já constitui um signo [...].

Freinet preocupava-se em trazer o mundo externo para o interior da escola, e mais, preocupava-se com as ricas vivências fora dos muros escolares, como parte do aprendizado das crianças, já que sua concepção de espaço jamais esteve limitada aos "cantinhos", como se dissemina de forma inapropriada nos meios pedagógicos. A ideia de espaço não é fixa em seu aspecto limitador, é móvel, e ademais, estende-se para a comunidade social na qual a escola está inserida.

Evidente está neste estudo que a concepção de espaço freinetiana permite reiterar a concepção de língua como um sistema vivo em contexto social, tão como depreendemos dos estudos do enfoque histórico cultural. Ao entender que o foco do ensino na letra, com base na sinalidade, não possibilita à criança o entendimento de que isso é linguagem, discordamos da ênfase no desenvolvimento do trabalho de 
alfabetização, ainda nos dias atuais, restrito às letras, aos sons destas e as suas sílabas, uma vez que nesta vertente há um reflexo limitador no modo como as crianças lidam com a língua escrita: primeiro elas buscam a identificação das letras, para depois buscar o sentido do que está sendo lido ou escrito.

Freinet parecia anunciar em suas técnicas possibilidades de mediações de práticas pedagógicas articuladas a conceitos russos vygotskianos e bakhtinianos, como os de linguagem, língua, ensino da leitura e da escrita, dentre outros. Não é sem razão a sua aposta no trabalho com a impressa na escola, com o texto livre, com a correspondência escolar, livro da vida, jornal de parede, etc. Chegou a realizar uma campanha intitulada "Abaixo aos manuais escolares". Para Freinet, se fosse para ler e/ou para escrever, teria que ser para "valer", de "verdade", para registrar, já que a nossa memória não guarda tudo; seria para comunicar-se com o outro, por exemplo, à distância. Isso é denotativo do próprio uso social da linguagem escrita, é representativo da função para a qual ela foi criada pelos homens. É a parte da própria atividade humana social e historicamente constituída.

Não foi por acaso que Freinet criou uma pedagogia do trabalho. Para ele, a atividade é o que orienta a prática escolar e o objetivo final da educação é formar cidadãos para o trabalho livre e criativo, capazes de dominar e de transformar o seu entorno e emancipar quem o exerce. Um dos deveres do professor, segundo Freinet, é criar uma atmosfera laboriosa na escola, de modo a estimular as crianças a fazer experiências, procurar respostas para suas necessidades e inquietações, ajudando e sendo ajudadas por seus colegas e buscando no professor alguém que organize o trabalho. Outra função primordial do professor, segundo Freinet, é colaborar ao máximo para o êxito de todos os alunos.

No processo de apropriação da cultura humana, o educador tem papel essencial, uma vez que para que a criança aprenda a usar um objeto da cultura - linguagem, objetos materiais e não materiais, instrumentos, técnicas, costumes e hábitos -, é necessário não só o objeto, mas a presença de alguém que saiba usá-lo e que efetivamente o use. A criança não aprende porque ouve alguém falando sobre um objeto, nem tampouco sozinha ou inventando um uso novo para o que encontra, mas porque atua sobre o objeto a partir de seu uso social que aprende com os outros. Leontiev em seu texto $O$ Homem e a Cultura, ilustra esta questão com um exemplo de Piéron.

RIAEE - Revista Ibero-Americana de Estudos em Educação, Araraquara, v. 13, n. 1, p. 155-174, jan./mar., 2018. 
Se o nosso planeta fosse vítima de uma catástrofe que só poupasse as crianças menores e na qual perecesse toda a população adulta, isso não significaria o fim do gênero humano, mas a história seria inevitavelmente interrompida. Os tesouros da cultura continuariam a existir fisicamente, mas não existiria ninguém capaz de revelar às novas gerações o seu uso. As máquinas deixariam de funcionar, os livros ficariam sem leitores, as obras de arte perderiam sua função estética. A história da humanidade teria de recomeçar. (PIÉRON, 1959, apud LEONTIEV, 1978b, p. 272).

Ou seja, sem aqueles que conheçam e efetivamente façam uso dos objetos da cultura, as novas gerações não poderiam apropriar-se destes objetos. O processo de apropriação do mundo - dos objetos e da cultura humanos - "é sempre activo do ponto de vista do homem". (LEONTIEV, 1978b, p. 268). Este processo é fruto da atividade reprodutiva, da atividade social para a qual o objeto da apropriação foi criado.

Para se apropriar dos objetos ou dos fenômenos que são o produto do desenvolvimento histórico, é necessário desenvolver em relação a eles 'uma actividade que reproduza, pela sua forma, os traços essenciais da actividade encarnada, acumulada no objeto.' (LEONTIEV, 1978b, p. 268)

Desta forma, tem papel essencial para a apropriação da cultura por cada ser humano seu convívio com as outras pessoas. Através da comunicação e das relações sociais que vai estabelecendo, a criança passa a conhecer e se apropriar dos objetos da cultura criados pela humanidade até o momento histórico no qual vive e que é partilhado pelo grupo social ao qual pertence. Aqui também residiam as preocupações freinetianas.

Diferentemente da maioria dos pedagogos modernos de sua época, o educador francês não via valor didático no erro. Ele acreditava que o fracasso desequilibra e desmotiva o aluno, por isso o professor deve ajudá-lo a superar o erro. "Freinet descobriu que a forma mais profunda de aprendizado é o envolvimento afetivo", diz a professora Rosa Sampaio, em documentário sobre a vida deste educador. Vygotsky em sua célebre palestra "o problema do entorno", de 1935 (2010), assegurava que a afetividade é central no aprendizado e no desenvolvimento da personalidade. (TOASSA, 2006).

Ao lado da pedagogia do trabalho e da pedagogia do êxito, Freinet propôs, finalmente, uma pedagogia do bom senso, pela qual a aprendizagem resulta de uma 
relação dialética entre ação e pensamento, ou teoria e prática. O professor se pautava por uma atitude orientada tanto pela psicologia quanto pela pedagogia - assim, o histórico pessoal do aluno interage com os conhecimentos novos e essa relação constrói seu futuro na sociedade.

Partindo-se das concepções de Freinet, a administração de situações inclusive conflituosas e/ou difíceis e afins poderia ocorrer a partir de uma resolução democrática, pautada na decisão coletiva dos alunos. Seria possível, para isso, construir um desenvolvimento laboral guiado "por votos de mão levantada" (FREINET, 1974, p. 21), no qual a realização de assembleias para votação de questões pertinentes tornar-se-ia uma ação periódica. Além disso, o levantamento de críticas, sugestões e elogios na produção em questão poderia apropriar-se das ideias de Freinet por meio de ações, conforme já pontuamos, em que "através de bilhetes, os alunos seriam estimulados a escrever, individualmente, suas opiniões na forma de 'eu proponho', 'eu critico' e 'eu felicito"”. Dessa maneira, seriam reunidas práticas para a organização das relações produtivas vivenciadas, auxiliando no alcance de um desenvolvimento mais lúcido e bem elaborado por parte dos alunos.

\section{As técnicas Freinet e o trabalho com as crianças na atualidade}

O objetivo deste tópico é apresentar o trabalho de pesquisa realizado em uma escola pública municipal do interior paulista, em que participaram crianças de cinco a seis anos de idade e sua respectiva professora. Para resguardar a identidade dos participantes, utilizaremos a letra $\mathrm{P}$ para designar a professora e $\mathrm{C}$ para designar as crianças $(\mathrm{C} 1 ; \mathrm{C} 2 ; \mathrm{C} 3)$, respectivamente.

A primeira cena que descrevemos ocorreu após a realização da roda da conversa em que as crianças contaram novidades, acontecimentos, fatos que viveram ou souberam por alguém. Foi escolhida nesse dia uma notícia da turma para criar um texto que faria parte do jornal. A primeira notícia era resultado de uma situação de pesquisa sobre o Sol - devido ao nome da Turma do Sol - que motivou inúmeras discussões, entrevistas, investigações das crianças na escola e que repercutiu nas ações pedagógicas e no envolvimento de toda a comunidade escolar ao envolver não somente as crianças, mas os professores, funcionários, diretora, coordenadora e os familiares dos sujeitos da pesquisa. 
Após a escolha unânime da notícia pelas crianças, foi criado um texto coletivamente, apresentado a seguir:

\section{PESQUISA SOBRE O SOL DEIXA TODO MUNDO CURIOSO NA ESCOLA}

A nossa Turma do Sol fez uma pesquisa que deixou todo mundo curioso na nossa escola. Essa pesquisa foi por causa de um cartão postal que nós recebemos de uma amiga que viaja muito chamada Suely. Ela foi para um lugar que se chama São Petersburgo lá na Rússia e que é bem longe daqui, mas longe mesmo.

Nesse lugar, quando é verão, o sol se põe às 11 horas da noite e nasce às 4 horas da manhã. Por que isso acontece?

Ninguém na escola sabe responder essa pergunta e olha que nós perguntamos para um montão de gente. Nem os nossos pais sabem, mas agora nós já sabemos porque nós pesquisamos com a nossa professora.

Você quer saber? No próximo jornal nós vamos contar tudo. Não percam!

(Texto criado em 26/10/10)

Terminada a escrita do texto criado pelas crianças, as negociações sobre os procedimentos seguintes ocorreram entre a professora e as crianças.

P: Pessoal, a primeira notícia que vocês escolheram na roda da conversa para escrevermos no jornal da nossa turma é sobre a pesquisa sobre o Sol, certo?

Todas: Certo.

C5: Pro, você deixa eu, C11 e C13 escrever esse texto no computador?

P: Por mim tudo bem. Vocês concordam que eles façam isso turma?

Todas: Concordamos.

C6: Então na hora de imprimir, você deixa eu te ajudar a fazer isso?

C2 e C9: Eu também quero.

P: Está certo. Depois, quando formos fazer a separação das folhas e montarmos o jornal, vamos precisar de mais ajuda.

C1, C7, C4: Eu ajudo!

Ao iniciar a digitação, C5 diz:

RIAEE - Revista Ibero-Americana de Estudos em Educação, Araraquara, v. 13, n. 1, p. 155-174, jan./mar., 2018. 
C5: Como eu faço para colocar a letra maiúscula pro? (olha para o teclado do computador e eu o oriento).

C5 digita quase inteiro o texto acompanhado de $\mathrm{C} 11$ e C13, quando em dado momento $\mathrm{C} 13$ diz:

C13: C5, você escreveu "e" e não "é".

C5: Eu escrevi sim.

C11: Não escreveu não. Olha aqui, você escreveu: "Nesse lugar, quando e verão" [...]

C13: É verdade.

C5: Mas onde eu escrevi isso?

(C11 aponta com o dedo indicador).

C5: Ah, mas é a mesma coisa.

C13: Não é não.

C5: Só esqueci do acento.

C11: Ah, mas se não põe o acento vira outra coisa.

C5: Ué? Como assim?

C13: Eu acho que o "E" é para falar as coisas e juntar o que está falando. O "É" é quando você fala que alguma coisa é assim, que é daquele jeito, sabe?

C5: Hum [...] sei lá $[\ldots]$

(C11 modifica e coloca o acento).

C13: Assim é melhor. Assim todo mundo vai entender direito a nossa notícia e vai querer que a gente escreva logo no outro jornal.

C11: Por enquanto vai ser só uma surpresinha essa notícia sobre a pesquisa sobre o Sol.

A escolha da notícia e principalmente a forma como ela é escrita denotam apropriação do gênero discursivo notícia. Segundo Jolibert (2006, p. 109), "notícias são informações sobre acontecimentos, eventos vigentes, dos quais se quer dar conhecimento aos leitores do jornal". Dessa forma, pode-se dizer que as crianças comunicaram por meio da notícia re-criada ${ }^{4}$ um acontecimento vivido por elas e que

\footnotetext{
${ }^{4}$ Neste trabalho, optamos por utilizar a expressão re-criar gêneros discursivos por entender que a criança, ao re-criar gêneros discursivos, cria-os e recria-os a partir do que já foi criado e apropriado da cultura humana. Entende-se que o ato de escrever, que envolve a imaginação, a criatividade está diretamente relacionada ao processo de apropriação da cultura humana e das experiências que a criança participa. A opção pelo uso dessa expressão também se justifica pela tentativa de estar em consonância com os pressupostos teóricos assumidos neste trabalho. Pensar em re-criador de gêneros discursivos é entender
}

RIAEE - Revista Ibero-Americana de Estudos em Educação, Araraquara, v. 13, n. 1, p. 155-174, jan./mar., 2018. 
possivelmente teve um sentido positivo, promotor de aprendizagens, dada a concordância de todas para que a notícia fosse escrita e levada a público por meio do jornal. Elas lidam com os elementos da notícia de forma interativa e aparentam perceber características específicas desse gênero. Isso pode ser observado no uso do discurso indireto em que "os índices de valoração do autor são mais visíveis por tratar-se de uma transmissão analítica do discurso do outro. É a marca direta do dialogismo e que aparece com mais frequência na notícia" (SILVA, 2008, p. 11-12). O discurso direto tem um estilo mais marcado porque tem a sua fala separada da do autor por aspas ou por dois pontos, com travessão. No discurso indireto esses limites são "apagados", funde-se com a fala do autor.

Como todo gênero discursivo, a notícia também se orienta para a resposta ativa do destinatário e se realiza a partir dessa atitude responsiva, porque as relações dialógicas se dão em razão do outro, do interlocutor, uma vez que é em função do destinatário real, vivo, responsivo que se constrói o discurso. Essa premissa é percebida no texto re-criado: "Ninguém na escola sabe responder essa pergunta e olha que nós perguntamos para um montão de gente. Nem os nossos pais sabem, mas agora nós já sabemos porque nós pesquisamos com a nossa professora. Você quer saber? No próximo jornal nós vamos contar tudo. Não percam!”.

Há que se destacar que as crianças trabalham de forma colaborativa, cooperativa e que por essa razão a interação entre elas, com a professora, com as pessoas presentes na escola, com o meio e com os materiais, promove aprendizagens porque elas estabelecem relações intensas. Nesse contexto, são ouvidas, e por meio das negociações feitas entre elas e a professora se organizam o trabalho pedagógico e as experiências a serem vividas. Esse fato é observado quando toda a turma participa da re-criação do texto coletivo e se encarrega em seguida das tarefas para a publicação do jornal que portará a notícia criada: C5, C11 e C13 se prontificam para digitarem o texto; C6, C2, C9 desejam participar da impressão; C1, C7, C4 solicitam separar as folhas para a montagem do jornal.

Sobre o uso das técnicas e da organização do trabalho pedagógico de forma cooperativa, Freinet $(1978$, p. 113) revela que "a criança, que se apercebe de que seu trabalho tem um objetivo e que pode abandonar-se completamente a uma actividade não

que o tão absolutamente novo é tão inconcebível como o absolutamente mesmo. (BAKHTIN, 1992, 2003). Nessa perspectiva, compreende-se a língua como algo vivo, em movimento, que se dá nas relações sociais, na interação com o outro, como criação da história e da cultura humanas, que se renovam e se reconstroem.

RIAEE - Revista Ibero-Americana de Estudos em Educação, Araraquara, v. 13, n. 1, p. 155-174, jan./mar., 2018. 
já escolar, mas simplesmente social e humana, sente-se invadida por uma forte necessidade de agir, de procurar, de criar". A livre expressão faz emergir na turma um clima de liberdade, autodisciplina e confiança (ELIAS, 1997). Ao solicitarem para digitar o texto, C5, C11 e C13 querem utilizar o computador da professora que ficava na sala para esse fim, bem como a impressora que tinha a função de reproduzir os textos para que todas pudessem ter o seu exemplar. Esse recurso corresponde à imprensa escolar. Para Freinet (1978, p. 112), “a imprensa está na base de um novo comportamento e de uma nova orientação da criança e do educador e, por conseguinte, de toda a pedagogia". E ainda afirma que:

\begin{abstract}
A Tipografia na Escola fez com que a expressão livre e a actividade criadora dos nossos alunos passasse para o domínio da prática quotidiana. Através da experiência, mais eficaz do que todos os raciocínios pretensamente científicos juntos, abriu novos horizontes a uma pedagogia baseada no interesse autêntico, fonte de vida e de trabalho. Restabeleceu de uma assentada a unidade do pensamento, da actividade e da vida infantis, como assinalávamos no nosso último artigo; integrou a escola no processo normal de evolução individual e social dos alunos. (FREINET, 1978, p. 113).
\end{abstract}

Apesar de Freinet se referir aos alunos da escola primária, sua pedagogia e técnicas de ensino podem adequar-se à pequena infância e a qualquer outro nível de ensino porque são calcadas em atitudes e valores humanizadores. O trabalho com a imprensa e o texto livre permitiram que pudessem discutir sobre elementos da língua e pensar em diferentes aspectos sobre ela. C5 digita o texto acompanhado por C11 e C13, que o alerta sobre a diferença entre "e" e "é". Inicialmente C5 diz que digitou corretamente por não perceber essa diferença quando diz: “Ah, mas é a mesma coisa". No entanto, C11 e C13 esclarecem que não se trata da mesma coisa e que a diferença entre elas altera o significado e o sentido do enunciado e, por consequência, a compreensão do que se quer expressar. C13 tenta explicar a diferença que existe entre "e" e "é" e aparenta compreender que "e" une as ideias dentro do texto - conjunção - e que "é" indica o estado de algo - o verbo ser.

C5: Só esqueci do acento.

C11: Ah, mas se não põe o acento vira outra coisa.

C5: Ué? Como assim?

RIAEE - Revista Ibero-Americana de Estudos em Educação, Araraquara, v. 13, n. 1, p. 155-174, jan./mar., 2018. 
C13: Eu acho que o "E" é para falar as coisas e junta o que está falando. O "É" é quando você fala que alguma coisa é assim, que é daquele jeito, sabe?

C5: Hum [...] sei lá [...]

(C11 modifica e coloca o acento).

C13: Assim é melhor. Assim todo mundo vai entender direito a nossa notícia e vai querer que a gente escreva logo no outro jornal.

O trabalho com os diferentes caracteres presentes no teclado do computador possibilita o manuseio da língua escrita e seus matizes. O leitor e o re-criador de textos do século XXI podem ter esse encaminhamento também na escola, já que lidam com essa diversidade fora dela por meio de telefones celulares de pessoas próximas da família, por exemplo. Bajard (2012, p. 86) explica que Freinet (1998), “há quase um século, preconizava a utilização da imprensa na escola para incentivar a conquista da escrita, a partir do manuseio tátil de caracteres, controlado pelos olhos”.

Por meio do manuseio dos caracteres no computador, C5 percebe que a "presença da letra maiúscula favorece a descoberta do sentido da escrita, já que a primeira letra fica sempre à esquerda" (BAJARD, 2012, p. 84-85). Isso se verifica quando a criança solicita à professora que o ensine a colocar a letra maiúscula no início do texto/do parágrafo. "Por essa particularidade, o objeto gráfico não se comporta exatamente como um objeto comum. Além dessa "lateralização" da escrita, a criança é levada a discriminar outras variáveis pertinentes, como os acentos" (BAJARD, 2012, p. 89-90), conforme ocorre com a situação apresentada com C5, C11 e C13. Para esse autor, os caracteres são capazes de acarretar uma mudança de sentido e há ainda que se considerar que "todos os caracteres possuem um valor visual, enquanto apenas uma parte desse conjunto apresenta um valor sonoro" (BAJARD, 2012, p. 86).

O uso da caixa alta no título apresenta a intenção de destacar o assunto a ser tratado, de chamar a atenção do leitor, e se distingue do corpo da notícia. "Há uma hierarquia muito evidente na tipografia: maiúsculas, minúsculas, tamanho, largura, disposição no espaço" (JOLIBERT, 2006, p. 110).

\section{A Leitura realizada durante uma Aula Passeio}

A situação de leitura de carta é apresentada para se compreender o processo de apropriação de leitura por meio do gênero carta. Com o objetivo de ampliar as 
experiências para que compreendessem todo o processo de emissão e de recepção da correspondência, a professora fez com as crianças uma aula-passeio à agência central dos Correios. As aulas-passeio são também uma das técnicas da Pedagogia Freinet. São saídas ao ar livre - aulas de campo - que oportunizam maior contato com o próprio meio, permitindo descobertas que motivam a re-criação dos textos livres.

Antes de postarem a carta aos correspondentes, pesaram, verificaram o valor e fizeram o pagamento da taxa. Em seguida foram conhecer por meio de um responsável a parte interna e o trabalho dos funcionários. Em meio a conversas e explicações de um monitor que acompanhavam esse passeio, três crianças pararam numa caixa em que as correspondências já estavam separadas para que o carteiro fizesse a entrega.

C7: Olha C6, que carta linda! Acho que é uma carta de amor (as crianças riem).

C6: Por que você acha isso?

C7: Porque tem um monte de adesivos de coração grudados no envelope e o envelope é vermelho.

C13: Ah, mas pode ser uma carta de amigas ou de amigos.

C7: Hum [...] não parece [...] parece de amor.

C13: Dá pra ler quem mandou (C13 lê o nome do destinatário) [...] é nome de homem $[\ldots]$

C6: Ih, mas e quem que está mandando? A gente precisava saber.

C13: Nem precisa [...] olha aqui (aponta com o dedo indicador direito) [...] está escrito aqui em cima: "Para o meu amor" (as crianças riem novamente).

A análise dos dados apresentados pela conversa entre as crianças denota que ao criar necessidades de leitura, o interesse por ler se manifesta em diferentes situações e que se aprende a ler em situações reais (JOLIBERT, 1994, 2006).

Quando as cartas são redigidas e os envelopes são preenchidos, as crianças entram em contato com modelos convencionais de escrita. [...] Como se pode perceber, com esse tipo de texto escrito, as crianças têm oportunidade de se apropriar de conteúdos culturais dos quais necessitará para inserir-se no processo de comunicação com outras pessoas. Isso inclui não só saber qual a função da carta, como é o seu trânsito de pessoa a pessoa, quanto custa esse trânsito, mas também, quais os recursos de escrita são necessários para que esse veículo de comunicação se concretize, o que implica a assimilação de certos

RIAEE - Revista Ibero-Americana de Estudos em Educação, Araraquara, v. 13, n. 1, p. 155-174, jan./mar., 2018. 
conceitos envolvidos nesse processo. (MILLER; MELLO, 2005, p. 13-14).

$\mathrm{Na}$ situação analisada, as crianças levantam suas hipóteses para saber se se trata de uma carta de amor por meio dos questionamentos que fazem no escrito do envelope e de outros elementos não verbais, como os adesivos de coração e a cor. No processo inicial de apropriação da leitura, as crianças buscam indícios no envelope para descobrirem informações e realizarem a leitura. Quanto a isto, ressalta-se que:

\begin{abstract}
A interpretação de um signo não pode coincidir somente com sua identificação, mas também requer compreensão ativa. $\mathrm{O}$ sentido de um signo consiste em algo mais, no que diz respeito aos elementos que permitem seu reconhecimento. É feito desses aspectos semânticoideológicos que são, em certo sentido, únicos, que tem algo de peculiar e de indissoluvelmente ligado ao contexto situacional da semiose. A compreensão do signo é uma compreensão ativa, pelo fato de que requer uma resposta, uma tomada de posição, nasce de uma relação dialógica e provoca uma relação dialógica: vive como resposta a um diálogo. (PONZIO, 2011, p. 186-187).
\end{abstract}

Ao considerar esses pressupostos, pode-se inferir que as crianças têm uma atitude responsiva, uma atitude leitora, uma vez que observam os elementos presentes no envelope, fazem inferências, questionam, opinam, dialogam com os dados percebidos e elaboram uma contrapalavra. Ao compreenderem os signos, participam de uma compreensão ativa.

\title{
Considerações finais
}

O ensino da leitura e da escrita se constitui numa preocupação sempre atual, que envolve pesquisadores, professores e pais. Inúmeros são os aspectos que provocam a reflexão sobre o processo de apropriação da linguagem escrita e sobre a relação com os espaços escolares, as práticas pedagógicas e as especificidades do ensinar e do aprender.

Com relação ao ensino e à aprendizagem da leitura e da escrita, Freinet esclarece que "a escrita só tem sentido se nos sentimos obrigados a recorrer a ela, a fím de comunicarmos o nosso pensamento fora do alcance da voz, para além das portas da escola". (FREINET, 1998, p. 53).

Por meio dessa pesquisa foi possível destacar que a utilização das técnicas Freinet no trabalho pedagógico não serviu apenas para fazer o aparecimento dos gêneros

RIAEE - Revista Ibero-Americana de Estudos em Educação, Araraquara, v. 13, n. 1, p. 155-174, jan./mar., 2018. 
discursivos que seriam abordados com as crianças - a carta, os relatos de vida, notícia de jornal -, mas permitiu a organização do fazer educativo de modo a possibilitar a interação entre as crianças, delas com a professora, com os materiais, criando uma aprendizagem provocadora de necessidades humanizadoras.

Com a utilização das técnicas Freinet foi possível promover uma aproximação com a ideias de Vygotski (1995) e de Bakhtin (1992), já que todos eles concebem a expressão do sujeito e a relação com o outro como elementos fundamentais da sua própria constituição como seres históricos, sociais e culturais.

A utilização das técnicas Freinet também permitiu maior autonomia das crianças para gerirem o tempo e as atividades, para opinarem, decidirem, discutirem, investigarem, pesquisarem sobre os diferentes assuntos que se faziam de interesse delas, porque essas técnicas promovem a aproximação da criança com a cultura, primando pela expressividade. Diante disso, os dados revelam que o trabalho com os gêneros discursivos no contexto das técnicas Freinet contribuiu para criar necessidades de ler e de escrever, porque as crianças sempre tinham o que dizer e para quem dizer.

A pedagogia Freinet e suas técnicas aliadas à teoria Histórico-Cultural e à teoria bakhtiniana podem contribuir para a efetivação de uma prática pedagógica promotora de aprendizagens.

Nesta pesquisa, as técnicas Freinet são compreendidas como um caminho para práticas que possibilitem a apropriação da cultura pela criança, por seu uso social, ou seja, para aquilo para o qual cada objeto da cultura foi criado e é utilizado socialmente. Desta maneira, são vistas como uma proposta alternativa para o trabalho na Educação Infantil que não antecipa o processo de escolarização, nem entrega ao espontaneísmo o desenvolvimento das crianças.

O uso das técnicas Freinet permite que a criança vivencie o papel das práticas sociais e participe da vida na escola, porque a apropriação da cultura se estabelece com o desenvolvimento de cada técnica, e as propostas têm maior possibilidade de se tornarem atividade (LEONTIEV, 1988) por envolverem a criança nesse fazer, porque os motivos que a levam a agir coincidem com o resultado previsto para sua ação e, por essa razão, pode produzir sentido positivo àquilo que realiza.

\section{REFERÊNCIAS}

BAJARD, E. A descoberta da língua escrita. São Paulo: Cortez, 2012.

RIAEE - Revista Ibero-Americana de Estudos em Educação, Araraquara, v. 13, n. 1, p. 155-174, jan./mar., 2018. 
BAKHTIN, M. Marxismo e filosofia da linguagem. $7^{\text {a }}$ ed. São Paulo: Hucitec, 1992.

BAKHTIN, M. Estética da criação verbal. Tradução Paulo Bezerra. São Paulo: Martins Fontes. 2003.

ELIAS, M. D. C. Célestin Freinet: uma pedagogia de atividade e cooperação. Petrópolis, RJ: Vozes, 1997.

FREINET, C. O jornal escolar. Lisboa: Editorial Estampa, 1974.

FREINET, C. As técnicas Freinet da escola moderna. 4. ed. Lisboa: Editorial Estampa, 1975.

FREINET, C. O método natural I: a aprendizagem da língua. Lisboa: Editorial Estampa, 1977.

FREINET, C. Nascimento de uma pedagogia popular. Lisboa: Editorial Estampa, 1978.

FREINET, C. A educação do trabalho. São Paulo: Martins Fontes, 1998.

PIÉRON, H. De l'Actinie à l'Homme. t. II. Paris, 1959. In: LEONTIEV. A. O desenvolvimento do psiquismo. Lisboa: Livros Horizonte, 1978, p.272.

JOLIBERT, J. Formando crianças leitoras. Tradução Walquíria M. F. Settineri e Bruno Charles Magne. Porto Alegre, Artes Médicas, v. II, 1994.

JOLIBERT, J. Além dos muros da escola: a escrita como ponte entre alunos e comunidade. Tradução Ana Maria Netto Machado. Porto Alegre: Artmed, 2006.

LEONTIEV, A.N. O desenvolvimento do psiquismo. Lisboa: Livros Horizonte, 1978.

LEONTIEV, A. N. Uma contribuição para a Teoria do Desenvolvimento da Psique Infantil. In: VIGOTSKI, L. S.; LURIA, A. R.; LEONTIEV, A. N. Linguagem, Desenvolvimento e Aprendizagem. SP: Ícone/EDUSP, 1988. p. 59 - 83.

MILLER, S.; MELLO, S. A. O desenvolvimento da linguagem oral e escrita em crianças de 0 a 5 anos. Curitiba: Pro-Infanti Editora, 2008 (Coleção Educação Infantil).

PONZIO, A. A revolução bakhtiniana; o pensamento de Bakhtin e a ideologia contemporânea. 1.ed. São Paulo: Contexto, 2011.

SAMPAIO, Rosa Maria W. Ferreira. Freinet: evolução histórica e atualidades. 2. ed. São Paulo: Scipione, 1994.

SILVA, J. C. As relações dialógicas no gênero notícia. In: Letra Magna - Revista Eletrônica de Divulgação Científica em Língua Portuguesa, Linguística e Literatura. Ano 04. n. 09. 2008. p. 1 - 18.

TOASSA, G. Emoções e Vivências em Vigotski. SP: Papirus, 2006.

RIAEE - Revista Ibero-Americana de Estudos em Educação, Araraquara, v. 13, n. 1, p. 155-174, jan./mar., 2018 
VIGOTSKI, L. S. A questão do meio (Sueli Amaral Mello, tradução). 2010 (mimeo trabalho original publicado em 1935).

VIGOTSKI, L. S. Linguagem, desenvolvimento e aprendizagem. 6. ed. São Paulo: Ícone: Editora da Universidade de São Paulo, 1998.

VYGOTSKI, L. S. La prehistoria del desarrollo del lenguagem escrito. In.:

VYGOTSKI, L. S. Obras Escogidas III: Problemas del desarrollo de la psique.

Madrid: Visor Distribuciones, S. A., 1995.

\section{Como referenciar este artigo}

GIROTTO, Cyntia Graziella Guizellim Simões.; FERREIRA DA SILVA, Greice.; MAGALHÃES, Cassiana. Freinet, Vigotsky e Bakhtin: uma aproximação possível ao acesso à cultura escrita. Revista Ibero-Americana de Estudos em Educação, Araraquara, v. 13, n. 1, p. 155-174, jan./mar., 2018. E-ISSN: 1982-5587.

Submetido em: 30/03/2017

Revisões requeridas: 20/04/2017

Aceito em: 30/06/2017 